\section{Original Research}

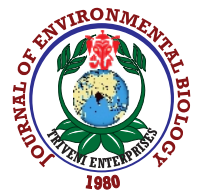

DOI : http://doi.org/10.22438/jeb/42/5/MRN-1748
Journal website : www.jeb.co.in $\star$ E-mail : editor@jeb.co.in Journal of Environmental Biology
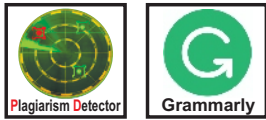

\title{
Micronuclei and other nuclear abnormalities in phorate exposed fish, Channa punctatus
}

\author{
S.P. Trivedi ${ }^{1{ }^{*}}$, A. Ratn', Y. Awasthi', N. Gupta', M. Kumar ${ }^{1}$ and A. Trivedi ${ }^{3}$ \\ 'Department of Zoology, Environmental Toxicology and Bioremediation Laboratory, University of Lucknow, Lucknow-226 007, India \\ ${ }^{2}$ C.S.J.M. University, Kanpur-208 024, India \\ ${ }^{3}$ Department of Animal Science, M.J.P. Rohilkhand University, Bareilly-243 006, India \\ *Corresponding Author Email : sat060523@gmail.com
}

\section{Abstract}

Aim: The present study aims to establish morphology-based nuclear abnormalities (NAs) including micronuclei (MN) as effective and sensitive genotoxic endpoint biomarkers in fish against the sub-lethal exposure of phorate.

Methodology: Fish, Channa punctatus $(35 \pm$ $3.0 \mathrm{~g} ; 14.5 \pm 1.0 \mathrm{~cm}$ ) were randomly exposed in two sets, treated group 1 and $2\left(0.0375 \mathrm{mg} \mathrm{l}^{-1}\right.$ and $0.075 \mathrm{mg} \mathrm{I}^{-1}$ of phorate, respectively) along with a simultaneous control $\left(0 \mathrm{mg} \mathrm{l}^{-1}\right)$. The blood was sampled after 30 days.

Results: A significant $(p<0.05)$ induction in reactive oxygen species (ROS) coupled with elevated frequency of blood cells showing micronuclei along with the gross appearance of notched nuclei, curved nuclei, blebbed nuclei, kidney-shaped nuclei, V-shaped nuclei, nuclear buds, nucleoplasmic bridges, dumbbell nuclei, and condensed/rounded nuclei were recorded in a dose-dependent manner.

Interpretation: The findings of present investigation can, thus, be reasonably employed as sensitive cytotoxic endpoint biomarkers as early warning tools to evaluate the genotoxicity induced by phorate in aquatic organisms, like fish.

Key words: Channa punctatus, Micronuclei, Molecular biomarkers, Nuclear abnormalities, Oxidative stress, Phorate

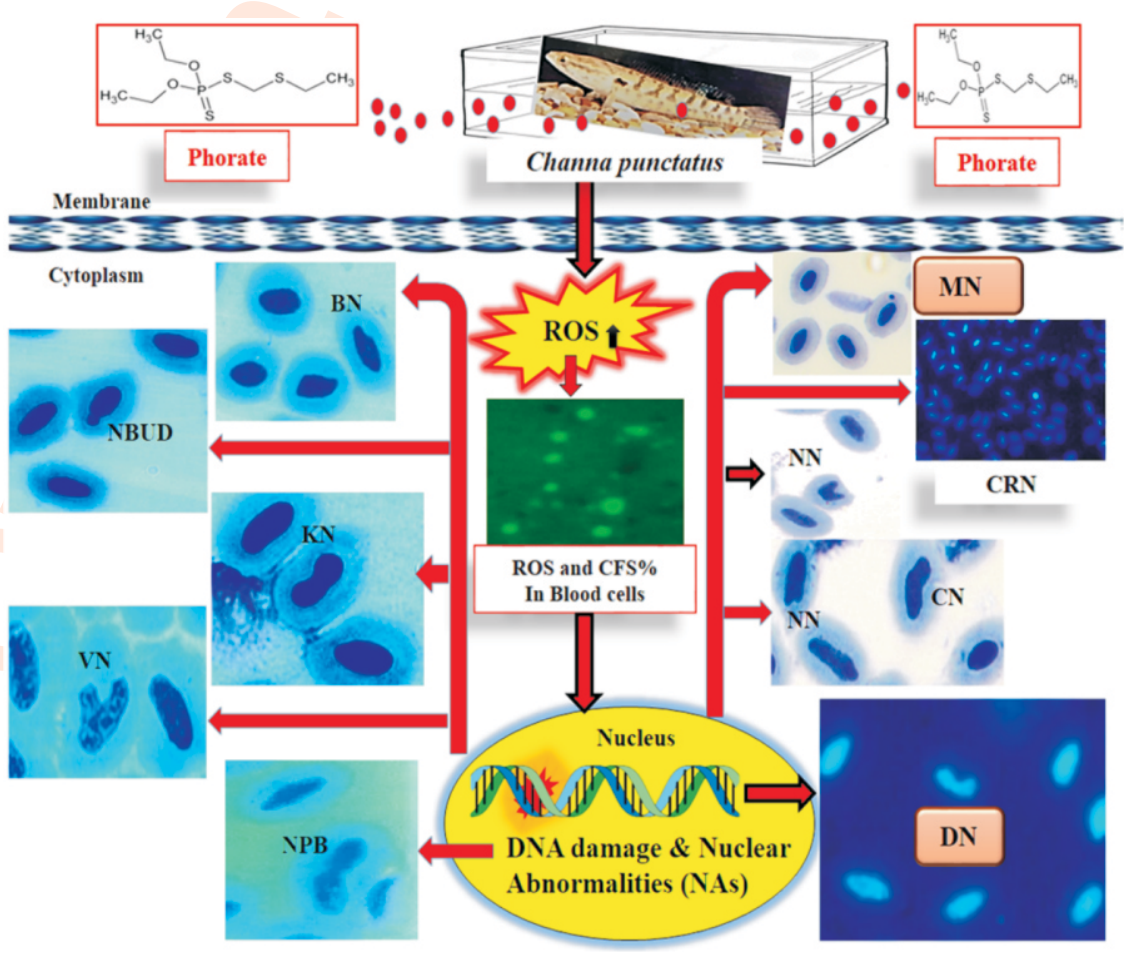

How to cite : Trivedi, S.P., A. Ratn, Y. Awasthi, N. Gupta, M. Kumar and A. Trivedi: Micronuclei and other nuclear abnormalities in phorate exposed fish, Channa punctatus. J. Environ. Biol., 42, 1221-1231 (2021). 


\section{Introduction}

Organophosphate pesticides (Ops), as crop protection chemicals, were introduced in India in the 1960s (Aktar et al., 2009). The nation consumes $76 \%$ of pesticides as insecticides, while the worldwide rate of their consumption is about $44 \%$ (Bhardwaj and Sharma, 2013). Further, in Asia, India ranks first in pesticide production and holds twelfth position in the world (Abhilash and Singh, 2009). Phorate, being a broad spectrum OP, is widely used against different pests (Myers et al., 2016). The WHO has classified phorate as one of the most hazardous pesticides of class I a in 2009. Phorate though has been banned or restricted in use in many countries, it is still used in India. This generates ecological constraints, particularly in non-target organisms of aquatic habitat (Mostafalou and Abdollahi, 2013).

During biotransformation, phorate primarily gets converted into an oxon, by cytochrome P450, which inhibits the activity of acetylcholinesterase (AChE) (Hodgson, 2012). The inhibition of AChE promotes ROS (reactive oxygen species) build-up and consequently enhances lipid per-oxidation and, thus, the oxidative stress, as evident in fish exposed to other crop protection chemicals, deltamethrin and cypermethrin (Slaninova et al., 2009). In fact, over production of ROS generates superoxide anions $\left(\mathrm{O}_{2}\right)^{-}$, hydrogen peroxide $\left(\mathrm{H}_{2} \mathrm{O}_{2}\right)$ and hydroxyl ions $\left(\mathrm{OH}^{-}\right)$(Saquib et al., 2012). Normally, these ROS are involved in cytoplasmic homeostasis by maintaining the cellular signaling pathways, however, their excess production contributes to oxidative stress leading to molecular damages via retrograde redox signaling among the cell organelles, i.e., mitochondria to cytosol and nucleus (Murphy, 2009). Further, extended subsistence of oxidative stress leads to genetic instability due to unresolved DNA repair complexes (larmarcovai et al., 2008). These instabilities in fish can be easily estimated by various nuclear anomalies/abnormalities that offer concrete information for DNA damage and genomic or chromatin instability triggered by xenobiotics. Earlier studies have also reported generation of aforementioned nuclear anomalies in fishes exposed to crop protection chemicals other than phorate (Ahmad and Ahmad, 2016). These nuclear anomalies can be adequately used for instant diagnosis of genotoxic damage in human beings too (Kirsch-Volders and Fenech, 2001).

Nuclear anomalies are mostly formed due to condensation of genetic material inside the nucleus and under the influence of mitochondrial factors. Among these, apoptosis inducing factor is the major one which is responsible for such condensation (Candé et al., 2002). Among nuclear abnormalities, micronuclei, a chromatinic body, is an outcome of the DNA strand breaks and/or formed by the condensation of chromatin fragments. Micronuclei assay is a rapid and extensively used technique to study the non-specific genomic damage (Trivedi et al., 2020). Moreover, micronuclei induction also indicates misrepair of DNA strand breaks (Klobučar et al., 2010). An elevation in micronuclei frequency was reported in fish exposed to a pesticide, fenvalerate (Chaudhari and Saxena, 2015) and also in blood cells of humans after their exposure to an herbicide 2, 4-dichlorophenoxyacetic acid (Holland et al., 2002).

Nuclear abnormalities promptly illustrate the induction of genotoxic damages in blood cells, especially erythrocytes of animals exposed to xenobiotics. They can be efficiently used for the diagnosis of chromosomal modifications (Thomas et al., 2003). These nuclear abnormalities may be considered better biomarkers than cytotoxic indicators due to their higher sensitivity and more perceptibility (Ahmad and Ahmad, 2016). In fact, to understand the eco-genotoxicological manifestations, nuclear abnormalities may be considered as genotoxic endpoint biomarkers. Further, the correlation approaches among aforesaid nuclear abnormalities and oxidative stress are adequately able to decipher the strength of relationships among them. Thus, the present study reflects ample prospects for less expensive and rapid screening methodologies for assessment of genotoxicological perturbations in fish for routine biomonitoring of contaminated aquatic habitats.

\section{Materials and Methods}

Fish collection and their acclimatization : For present study, live and active fishes $(35 \pm 3.0 \mathrm{~g} ; 14.5 \pm 1.0 \mathrm{~cm})$, C. punctatus, were hand netted with the help of local fishermen from suburban aquatic habitats of Lucknow, India. In the laboratory, initially, fishes were dipped in $0.05 \%$ solution of potassium permanganate $\left(\mathrm{KMnO}_{4}\right)$ for 4 min to get rid of epidermal contagions. Fish were subjected for acclimatization. Food pellets (Perfect Companion Group Company Limited, Thailand) at a rate of $2 \%$ of body weight were provided to fishes, daily. Feeding was discontinued for one day before in-vivo experiment.

Experimental design : For in-vivo study, 30 specimens were randomly distributed into three groups: control $\left(0 \mathrm{mg} \mathrm{l}^{-1}\right), \mathrm{T} 1$ $\left(0.0375 \mathrm{mg} \mathrm{l}^{-1}\right)$ and $\mathrm{T} 2\left(0.075 \mathrm{mg} \mathrm{l}^{-1}\right)$, each containing 10 specimens. The dose of phorate selected for T1 $\left(0.0375 \mathrm{mg} \mathrm{l}^{-1}\right)$ and T2 $\left(0.075 \mathrm{mg} \mathrm{l}^{-1}\right)$ were 20 and 10 times lower to reported $\mathrm{LC}_{50}$ value $0.75 \mathrm{mg} \mathrm{I}^{-1}$ for $C$. punctatus (Ratn et al., 2017). Experiments were run in triplicate for 30 day and fish were fed only with maintenance feed at 7 day intervals. Every day, food remains and excretory wastes were removed from each aquaria. After 30 days, fish were anaesthetized with $0.01 \%(\mathrm{v} / \mathrm{w})$ diethyl ether. Blood sampling was done in ethylenediaminetetraacetic acid (EDTA; $1.8 \mathrm{mg} \mathrm{ml}^{-1}$ ) coated vials through heart puncture by using a heparinized syringe for assessment of ROS and associated nuclear abnormalities.

Estimation of ROS and CFS : The phorate-induced ROS activity in erythrocytes of $C$. punctatus and subsequent fluorescence were estimated by employing 2', 7'-dichlorodihydrofluoresceindiacetate (20 $\mathrm{MM}$, DCFH-DA; Sigma Aldrich, USA) dye and a 
fluorescent microscope, respectively, by following the modified method (Ratn et al., 2018). Two thousand cells were counted to quantify the percentage of erythrocytes showing ROS-induced fluorescent signals (CFS).

Evaluation of nuclear abnormalities : Phorate induced chromosomal breakage or loss of whole chromosome in terms of micronuclei induction, and aforesaid nuclear abnormalities were assessed in fish of each group. The collected blood was evenly spread over pre-cleaned and pre-heated $\left(40^{\circ} \mathrm{C}\right)$ glass slides for each fish, slides prepared in triplicate were processed for the estimation of frequencies of micronuclei and other nuclear abnormalities.

Analysis of dumbbell nuclei and condensed/rounded nuclei: The phorate-induced dumbbell nuclei and condensed/rounded nuclei in erythrocytes of fish were analyzed by using Hoechst 33342 fluorescent dye (Sigma Aldrich, USA). The blood samples from each fish were transferred in EDTA coated vials using a heparinized syringe. After further processing, blood cells containing dumbbell nuclei and condensed/rounded nuclei were observed and scored. At least 2000 cells were counted and the frequencies of dumbbell nuclei and condensed/rounded nuclei were calculated.

Statistical analyses : The data were statistically analyzed at $p<$ 0.05 . They were displayed as mean \pm standard error mean (S.E.M.). The values of various parameters of treated and control groups were evaluated by employing one-way analysis of variance (ANOVA) followed by Tukey's post hoc test. The data of studied parameters were analyzed by Statistical Package for the Social Sciences (SPSS) software (version 20.0, Chicago, IL, USA). Regression and correlation analyses were also established to find out the compact relationships between nuclear abnormalities and reactive oxygen species.

\section{Results and Discussion}

In comparison to control, ROS activity and CFS percentage significantly $(p<0.05)$ elevated in phorate treated groups, T1 (0.0375 $\left.\mathrm{mg} \mathrm{l}^{-1}\right)$ and T2 (0.075 $\left.\mathrm{mg} \mathrm{l}^{-1}\right)$ after 30 days (Fig. 1). Fold change in ROS activity was significantly $(p<0.05)$
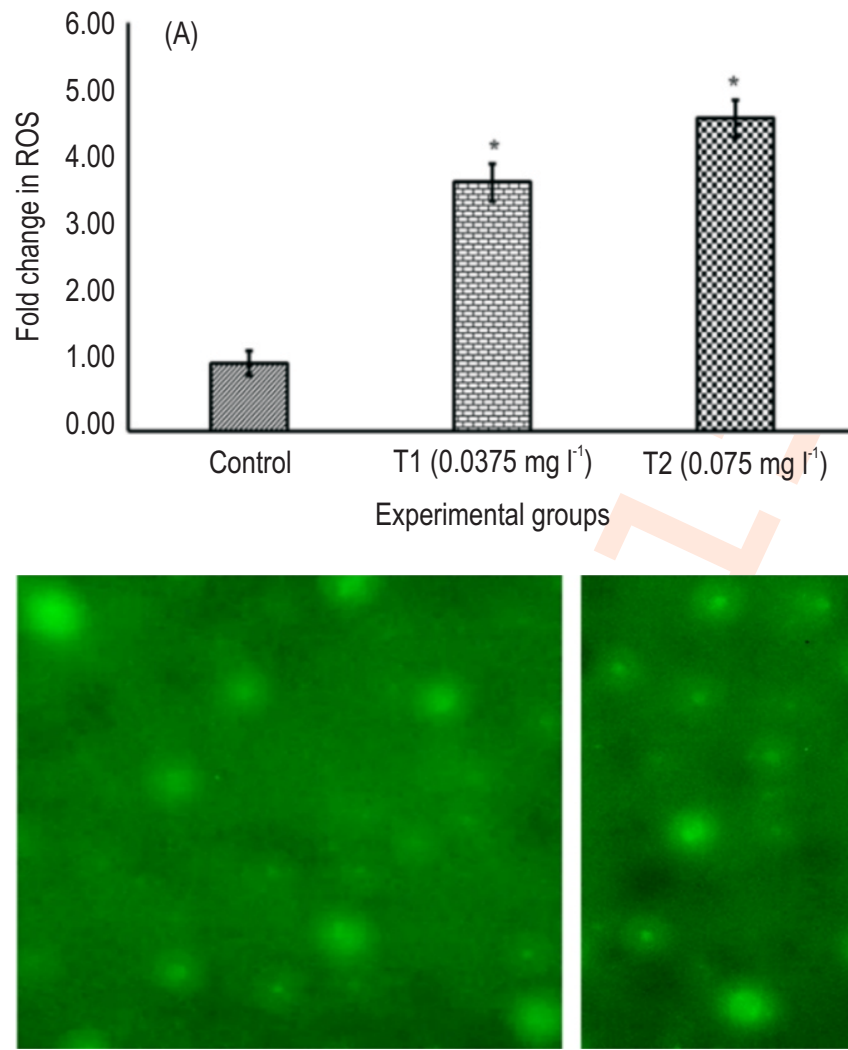

(C) Control

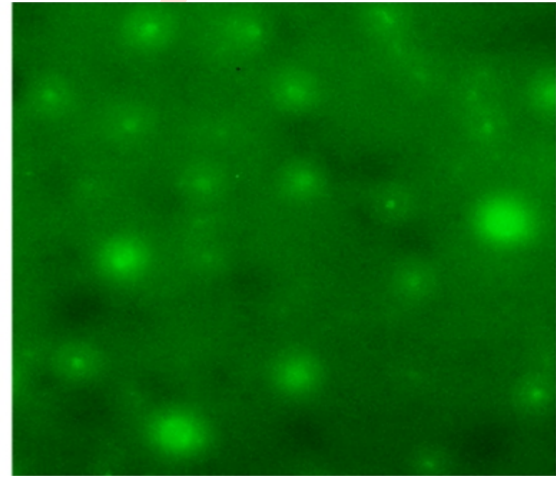

(D) T1 $\left(0.0375 \mathrm{mg} \mathrm{l}^{-1}\right)$

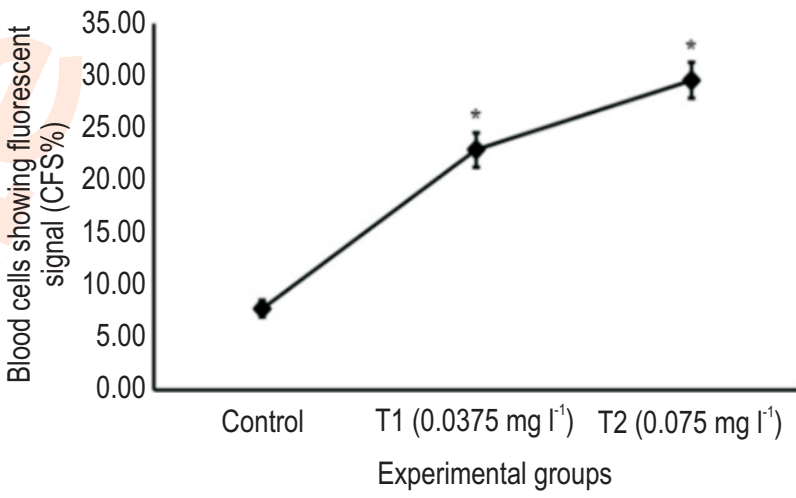

Fig. 1 : Representative graphs displaying a significant $(p<0.05)$ induction in ROS level $(A)$ and the frequencies of erythrocytes showing fluorescent signals (CFS) (B) in phorate exposed C. punctatus of treated groups (T1 and T2) in comparison to control. The photographic images of erythrocytes showing ROS induced fluorescence in T1 (D) and T2 (E) groups in comparison to control (C) by using DCFH-DAdye (20 $\mu \mathrm{M})$ after $30 \mathrm{~d}$. Values are mean \pm SEM of 9 fish from each group. ${ }^{*}$ indicated significance at $p<0.05$ of treated against control. 
enhanced $3.66 \pm 0.28$-fold (T1) and $4.59 \pm 0.28$-fold (T2) in phorate exposed erythrocytes of fish in comparison with the control (Fig. 1A). The frequencies of erythrocytes showing fluorescent signal (CFS), produced by ROS, were significantly ( $p$ $<0.05$ ) increased 1.94-fold (T1) and 2.79-fold (T2) in phorate treated erythrocytes of fish in comparison with the control (Fig. 1B). The demonstrative photographic images of erythrocytes clearly display an elevation in ROS activities exhibiting fluorescent signal (CFS\%) in phorate treated fish of T1 (Fig. 1D) and T2 (Fig. 1E) groups in comparison with unexposed group in a dose-dependent manner after 30 days (Fig. 1C). In context with this finding, an increase in reactive oxygen species was also described in fish Cyprinus carpio after long-term exposure to terbutryn (Velisek et al., 2011).

The frequencies of micronuclei (MN) significantly $(p<$ 0.05) elevated in phorate-exposed erythrocytes of fish of both T1 and $\mathrm{T} 2$ in comparison with control in a dose-dependent manner after 30 days (Fig. 2). The frequencies of MN elevated 9.55-fold (T1) and 13.15-fold (T2) in phorate exposed erythrocytes of fish in comparison with control (Fig. 2A). The photographic images evidently illustrate the phorate-induced micronuclei (MN) in erythrocytes of fish of T1 (Fig. 2C) and T2 (Fig. 2D) groups in comparison with the control (Fig. 2B) after 30 days of treatment. Similarly, the elimination of amplified DNA, chromosome or telomeric DNA damage and complete chromosome loss are the molecular phenomena that are instrumental in generation of MN, i.e., mini-circles of acentric chromatinic body (Podrimaj-Bytyqi et al., 2018). Notably, the main nucleus budded off or excluded the excess chromatin material or amplified DNA by certain active processes such as misrepair of DNA breaks and mal-segregation of chromosomes at anaphase to form a micronucleus (Fenech et al., 2011). This improper segregation of chromosome takes place due to inappropriate attachments of kinetochore-microtubules during the cell division (Godek et al., 2015). Several instances are there to record $M N$ induction after exposure to different xenobiotics (Awasthi et al., 2018; Pandey et al., 2014; Yadav and Trivedi, 2009). The pesticides induced chromatin instability in terms of MN induction has also been reported in blood cells of humans (Coskun et al., 2011) and fish (Tiwari and Trivedi, 2019;

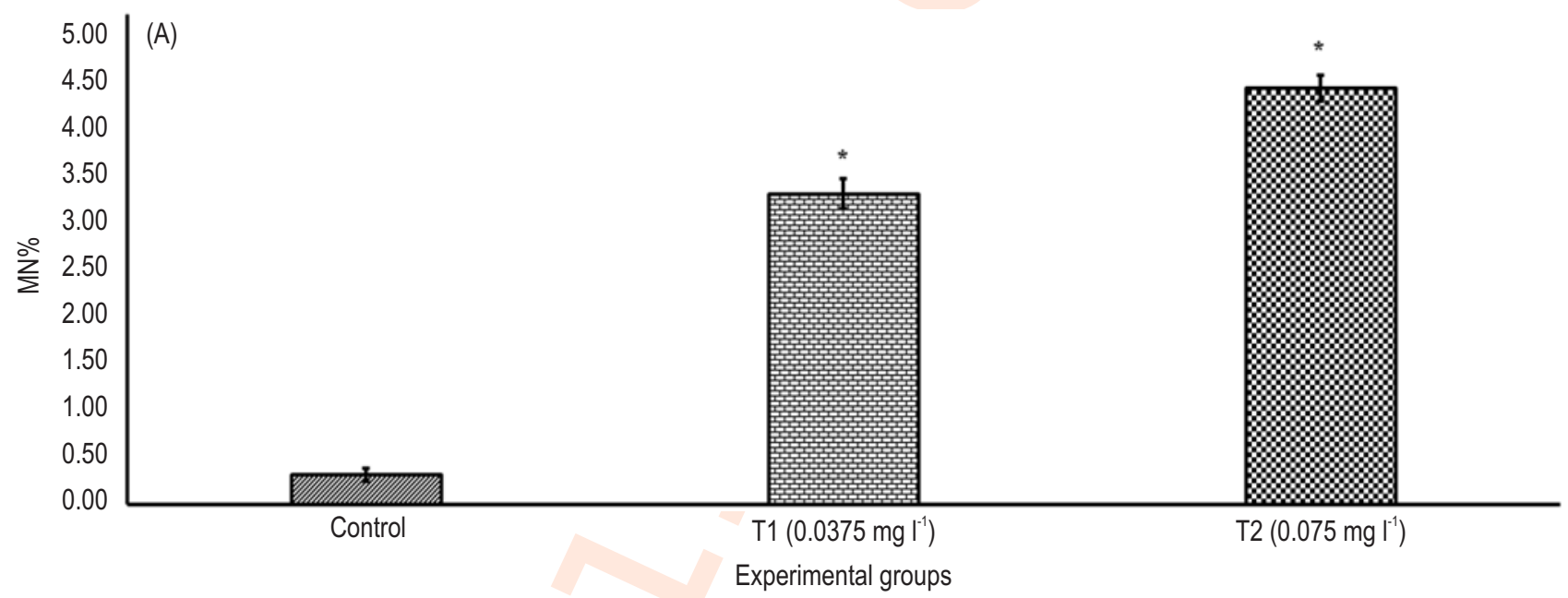

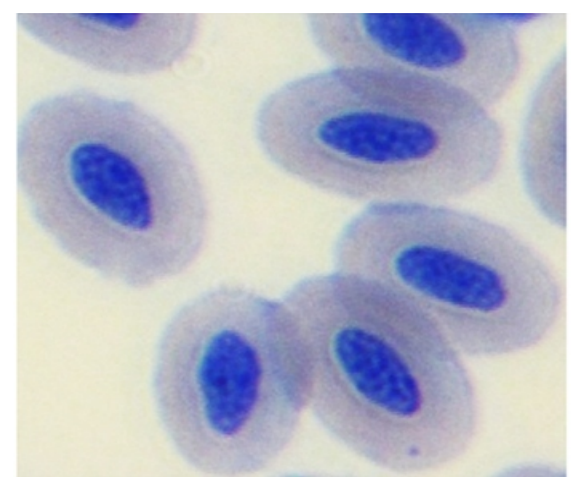

(B) Control

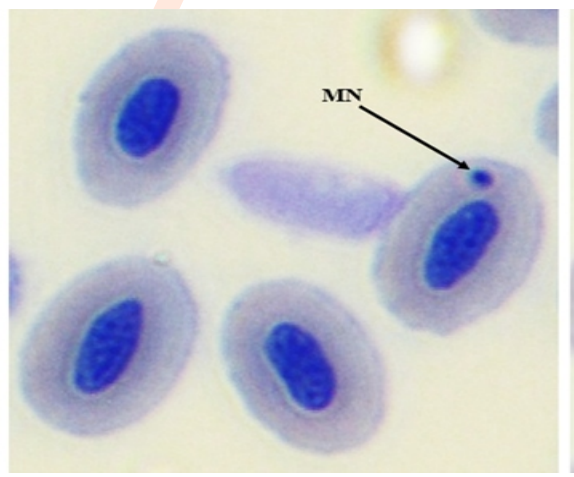

(C) T1 $\left(0.0375 \mathrm{mg} \mathrm{l}^{-1}\right)$

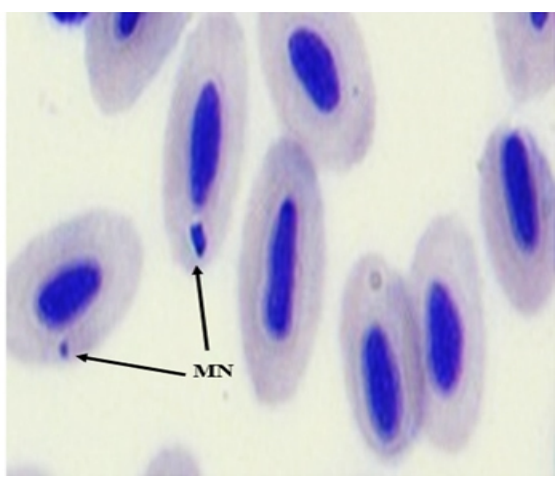

(D) $\mathrm{T} 2\left(0.075 \mathrm{mg} \mathrm{l}^{-1}\right)$

Fig. 2 : (A) Graph showing a significant $(\mathrm{p}<0.05)$ induction in the frequencies of micronuclei $(M N)$ in phorate treated groups ( $T 1$ and $T 2)$, in comparison to control after $30 \mathrm{~d}$. The photographic images of erythrocytes showing MN, in T1 (C) and T2 (D) in comparison with control (B), by using $0.125 \%$ MayGrunnwald's dye and followed by $5 \%$ Giemsa stain. Values are mean \pm SEM of 9 fish from each group. * indicated significance at $p<0.05$ of treated against control. 
Trivedi etal., 2021).

The frequencies of notched nuclei (NN) and curved nuclei (CN) significantly $(p<0.05)$ elevated in phorate-exposed erythrocytes of fish of T1 and T2 in contrast to control after an exposure of 30 days (Fig. 3). Phorate-induced notched nuclei (NN) (Fig. 3B) and curved nuclei (CN) (Fig. 3C) in erythrocytes of fish of T2 $\left(0.075 \mathrm{mg} \mathrm{l}^{-1}\right)$ group are markedly visible in comparison with the control (without NAs) (Fig. 3A). The frequency of notched nuclei (NN) significantly $(p<0.05)$ elevated 2.77 -fold (T1) and 3.95 -fold (T2) in phorate induced erythrocytes of test fish in comparison with control in a dose-dependent manner (Fig. 3D). Notably, notched nuclei (NN) generated due to incomplete invagination or noticeable deepness inside the nucleus and Ateeq et al., (2002) have also described this NA in blood cells of catfish, C. batrachus. This is pertinent to mention here that tubulin polymerization perturbations (TPP) induced aneugenic activity was recognized as one of the main reasons for the generation of notched nuclei (Chondrou et al., 2018). Besides notched nuclei, the frequency of curved nuclei $(\mathrm{CN})$ significantly $(p<0.05)$ increased 2.17-fold (T1) and 3.68-fold (T2) in phorate exposed erythrocytes of fish in comparison with control in a dosedependent manner (Fig. 3E). Also, its related outcomes were described in freshwater fish Australoheros facetus after shortterm exposure to endosulfan (Crupkin et al., 2013).

The microphotographic images of phorate exposed erythrocytes of fish evidently display the blebbed nucleus (BN) (Fig. 4B), nuclear bud (NBUD) (Fig. 4C), kidney-shaped nucleus (KN) (Fig. 4D), V-shaped nucleus (VN) (Fig. 4E) and nucleoplasmic bridge (NPB) (Fig. 4F) in test fish of T2 $\left(0.075 \mathrm{mg} \mathrm{l}^{-1}\right)$ group in comparison with the control (without NAs) (Fig. 4A) after a treatment time of 30 days (Fig. 4).

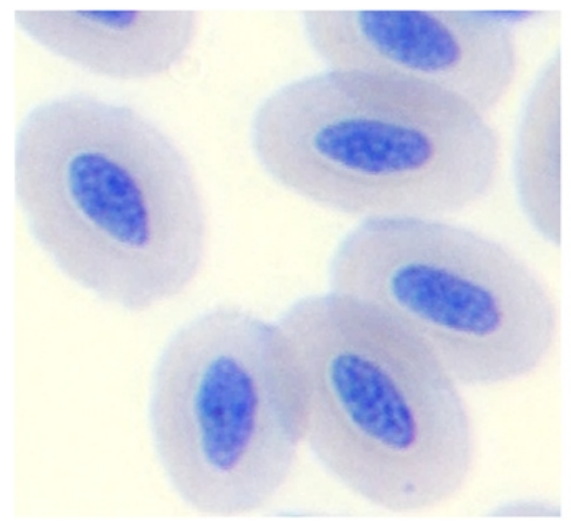

(A) Control (without NAs)

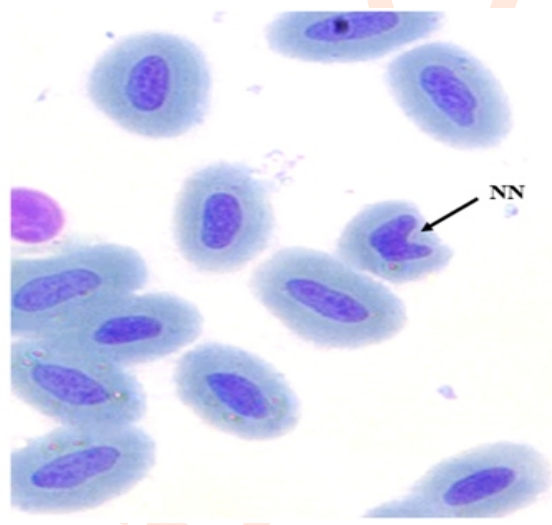

(B) Notched Nucleus (NN)

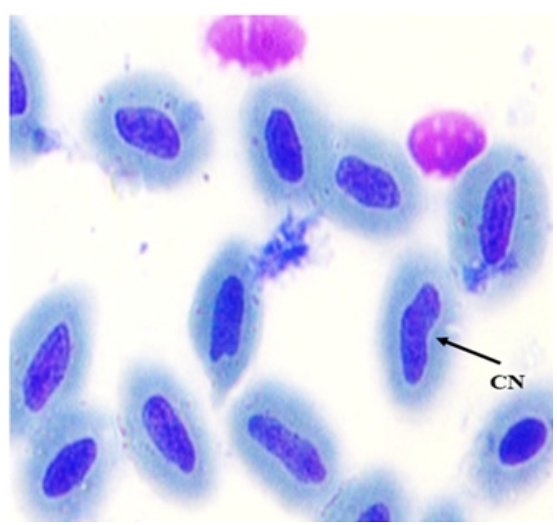

(C) Curved Nucleus (CN)
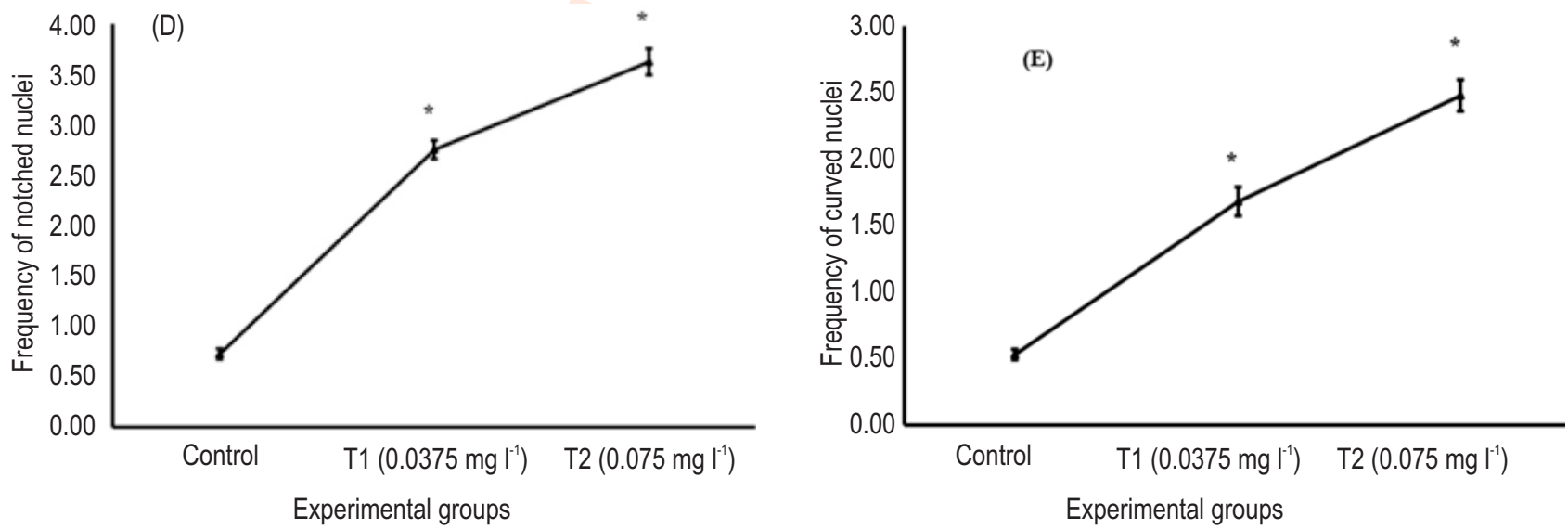

Fig. 3 : Representative images of erythrocytes showing a notched nucleus (NN) $(B)$ and curved nucleus $(C N)(C)$ in phorate treated fish in comparison to control (without NAs) (A) by using $0.125 \%$ May-Grunnwald's dye, followed by $5 \%$ Giemsa stain. Representative graphs illustrate a significant $(p<0.05)$ induction in frequencies of notched nuclei (NN) (D) and curved nuclei (E) in phorate exposed erythrocytes of fish of T1 and T2 as compared to control after $30 \mathrm{~d}$. Values are mean \pm SEM of 9 fish from each group. * indicated significance at $p<0.05$ of treated against control. 
The frequencies of nuclear anomalies (NAs) viz., blebbed nuclei (BN), nuclear buds (NBUD), kidney-shaped nuclei (KN), Vshaped nuclei (VN) and nucleoplasmic bridges (NPB) significantly $(p<0.05)$ elevated in phorate exposed erythrocytes of fish, C. punctatus of T1 $\left(0.0375 \mathrm{mg} \mathrm{l}^{-1}\right)$ and T2 $\left(0.075 \mathrm{mg} \mathrm{l}^{-1}\right)$ in comparison with the control in a dose-dependent manner after 30 $\mathrm{d}$ of exposure period (Fig. 5). The frequency of blebbed nuclei (BN) significantly $(p<0.05)$ increased 1.25-fold (T1) and 2.75-fold (T2) in phorate exposed erythrocytes of fish in comparison with the control (Fig. 5A). At the cellular level, amplified DNA or chromatin material slightly localizes upon the periphery of the nucleus and is termed as blebbed nuclei (BN). This class of NAs is identified as a minor evagination of amplified DNA or affected chromatin material through the process of exocytosis. After getting surrounded by a membrane, the evagination becomes BN (Fenech, 2006). In context with BN, Weldetinsae et al. (2017) have emphasized that the phenomenon acknowledged as breakage-fusion-bridge cycle was primarily responsible for bulging of amplified DNA or chromatin from the nucleus. Apart from blebbed nuclei, the frequency of kidney-shaped nuclei (KN) was significantly $(p<0.05)$ increased 1.00 -fold (T1) and 2.52-fold (T2) in phorate exposed blood cells, especially erythrocytes of fish in comparison control (Fig. 5C). Previously, several studies have reported the elicited frequency of kidney-shaped nuclei in different pesticides induced fish species (Ahmad and Ahmad, 2016; Marques et al., 2014). Successively, the frequency of Vshaped nuclei was also significantly $(p<0.05)$ elevated 1.99 -fold (T1) and 5.13-fold (T2) in phorate exposed erythrocyte of fish in comparison with the control (Fig. 5D). As well as, the findings are also in agreement with that of da Silva Souza and Fontanetti (2006) who have documented NAs in blood cells of Nile tilapia intoxicated with refinery effluent in contaminated aquatic environments. Moreover, the frequency of nuclear buds (NBUD) significantly $(p<0.05)$ elevated 1.94-fold (T1) and 3.37-fold (T2) in phorate induced erythrocytes of test fish in comparison with control (Fig. 5B). Further, the frequency of nucleoplasmic bridge (NPB) significantly $(p<0.05)$ increased 1.55-fold (T1) and 3.42fold (T2) in phorate exposed erythrocytes of fish, Channa punctatus in comparison with the control in a dose-dependent manner after $30 \mathrm{~d}$ (Fig. 5E). In the present study, the frequency of

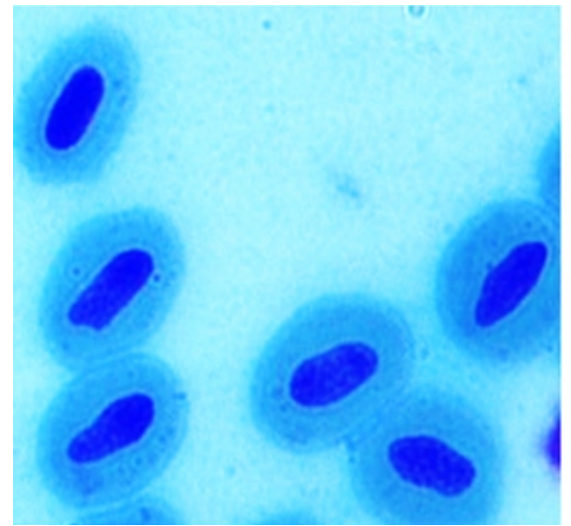

(A) Control (without NAs)

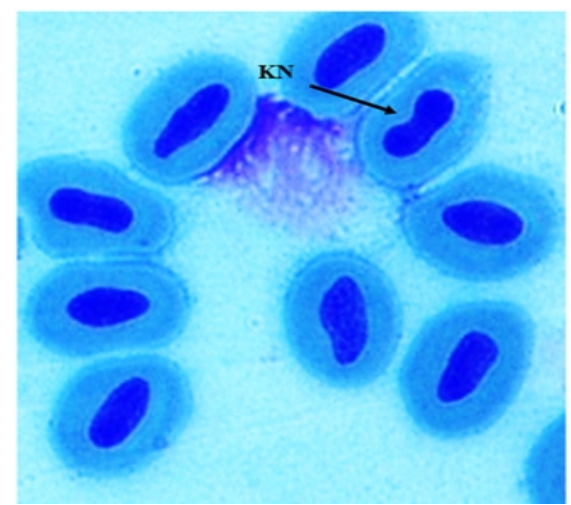

(D) Kidney-shaped Nucleus (KN)

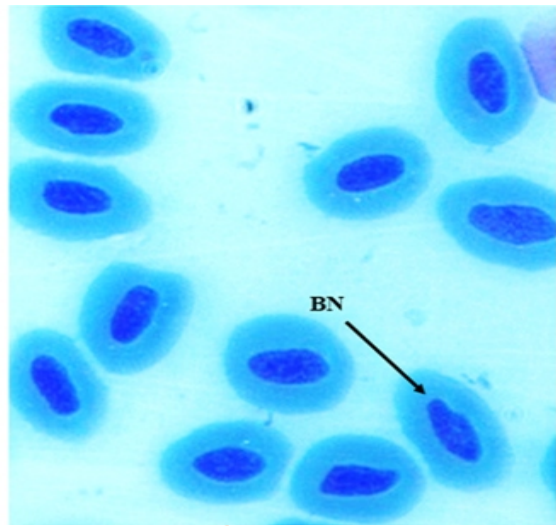

(b) Blebbed Nucleus (BN)

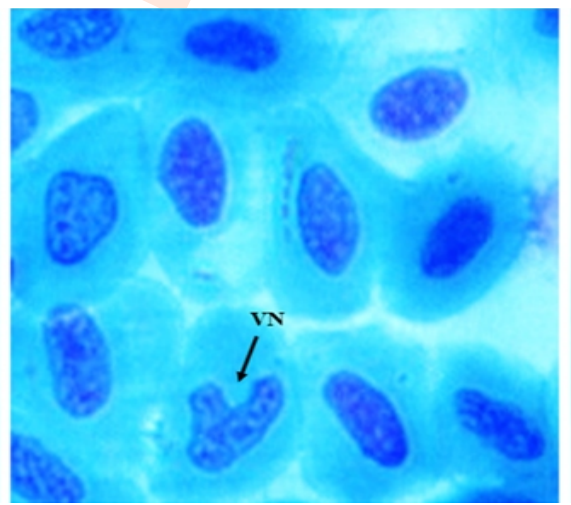

(E) V-shaped nucleus (VN)

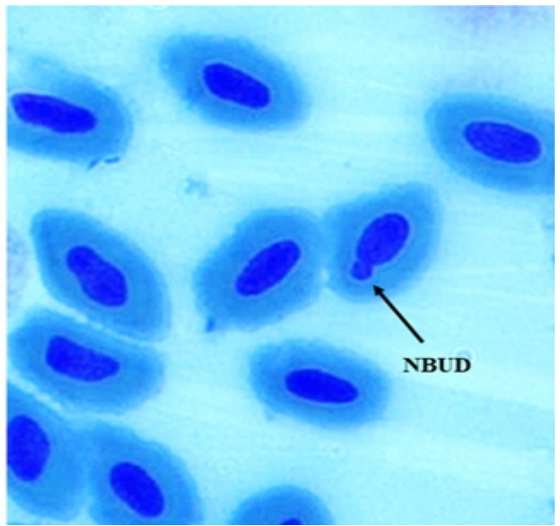

(C) Nuclear Bud (NBUD)

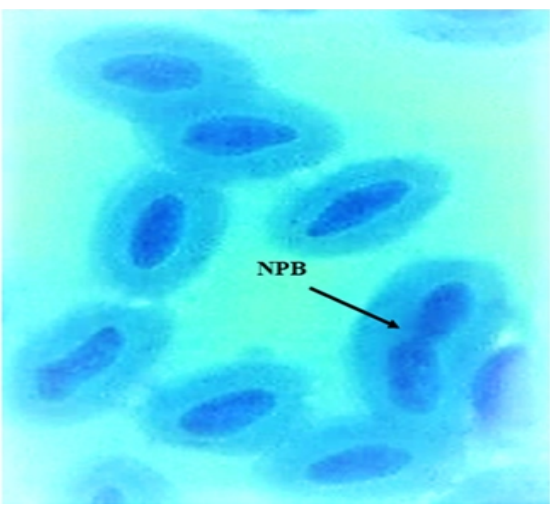

(F) Nucleoplasmic bridge (NPB)

Fig. 4 : Demonstrative photographic images of erythrocytes showing blebbed nucleus (BN) (B), nuclear bud (NBUD) (C), kidney-shaped nucleus (KN) (D), V-shaped nucleus (VN) (E) and nucleoplasmic bridge (NPB) (F) in phorate exposed fish in comparison to control (without any NAs) (A) by using $0.125 \%$ May-Grunnwald's dye, followed by $5 \%$ Giemsa stain, after $30 \mathrm{~d}$. 
both NBUD and NPB were found significantly $(p<0.05)$ elevated in erythrocytes of phorate exposed fish (T1 and T2) in comparison with the control in a dose-dependent mode. Correspondingly, Serrano-García and Montero-Montoya, (2001) have also observed induction in the frequency of chromatin buds $(\mathrm{CHB})$ in lymphocytes of smokers exposed to drugs. Actually, NBUD is formed through major evagination of euchromatin or amplified DNA bounded by membrane, while NPB originates by partial segregation of genetic material or euchromatin or partial karyokinesis (Garaj-Vrhovac et al., 2008). These nuclear anomalies represent incomplete evagination of certain parts of genomic DNAand misrepair or telomere end-fusions. Further, it is well established that NBUD is generated by evagination of
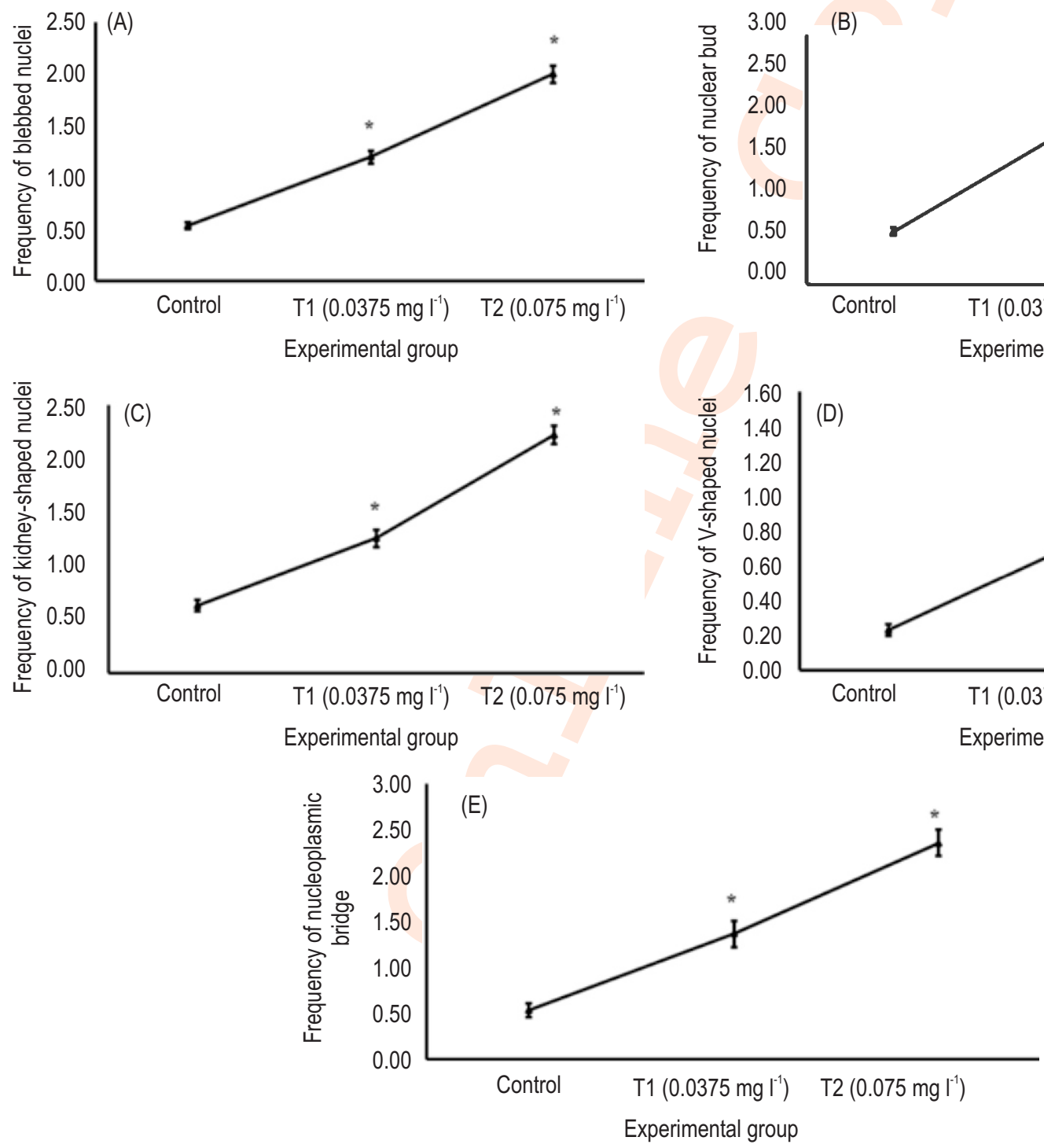

Fig. 5 : Demonstrative graphs showing a significant $(p<0.05)$ induction in frequencies of blebbed nuclei $(B N)(A)$, nuclear bud (NBUD) (B), kidneyshaped nuclei (KN) (C), V-shaped nuclei (VN) (D) and nucleoplasmic bridge (NPB) (E) in phorate exposed erythrocytes of fish of T1 and T2 in comparison to control after $30 \mathrm{~d}$. Values are mean \pm SEM of 9 fish from each group. * indicated significance at $p<0.05$ of treated against control. chromatin material (from nucleus) consisting $44 \%$ of telomeric DNA exclusively and $10 \%$ of both telomeric and centromeric DNA (Lindberg et al., 2007). Thus, it can be inferred that both NBUD and NPB are generated due to failure of DNA repair and inactivation of essential mechanisms required for removal of misrepair complexes. Marques et al. (2014) and da Rocha et al. (2011) elaborated the induction of nuclear anomalies in deltamethrin exposed Anguilla anguilla and in potassium dichromate exposed Oreochromis niloticus, respectively.

Evidently, the characteristic photographic images demonstrate phorate-induced dumbbell nucleus (DN) in erythrocytes of test fish of T2 $\left(0.075 \mathrm{mg} \mathrm{l}^{-1}\right)$ group (Fig. 6B) in
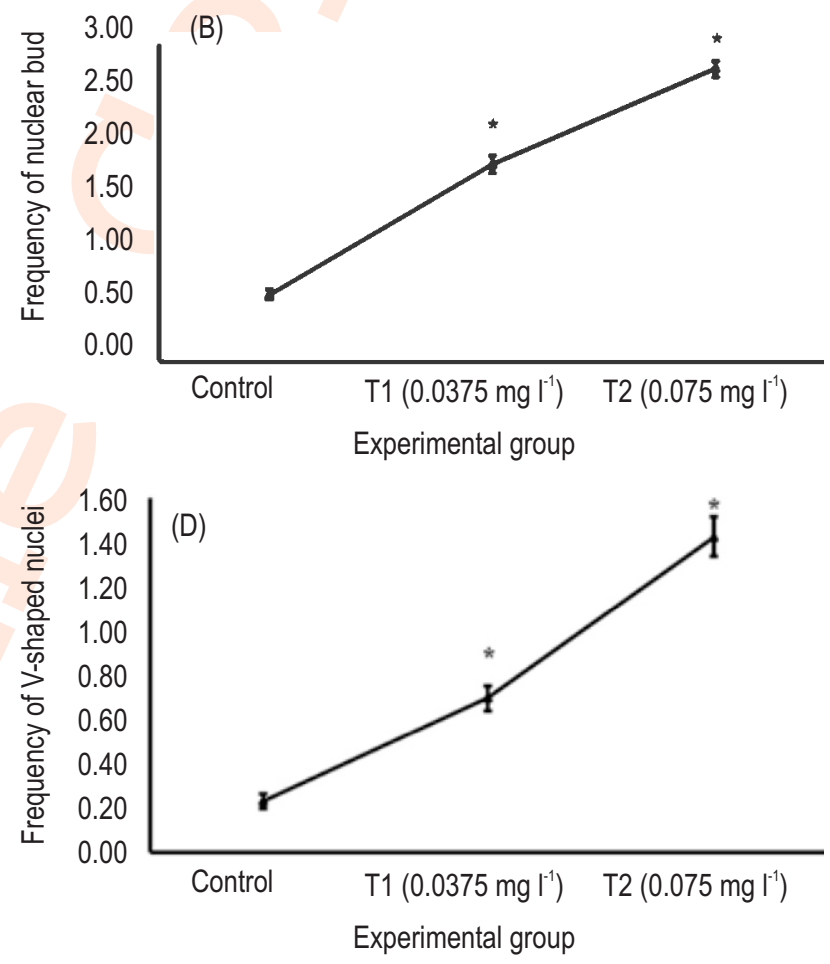
comparison with the control (without any NAs) (Fig. 6A) after 30 days of treatment (Fig. 6). The frequency of dumbbell nuclei (DN) significantly $(p<0.05)$ increased 1.70-fold (T1) and 3.91-fold (T2) in phorate exposed erythrocytes of fish in comparison with the control in a dose-dependent manner after 30 days of exposure period (Fig. 6C). Increased frequencies of dumbbell nuclei have also been reported by Falfushynska et al., (2013) in a fresh water bivalve, Anodonta anatina against its exposure to trace metals.

The frequency of condensed/rounded nuclei (CRN) were significantly $(p<0.05)$ induced in phorate exposed erythrocytes of fish of $\mathrm{T} 1$ and $\mathrm{T} 2$, in contrast, to control after 30 days of treatment time (Fig. 7). Notably, blood cells containing CRN illustrate early stage of apoptosis. The frequency of condensed/rounded nuclei (CRN) elevated 2.78-fold (T1) and 4.80-fold (T2) in phorate treated fish in comparison with the control (Fig. 7A). It is well known that CRN, a biomarker of early apoptosis, is recognized as a whole chromatin material inside the nucleus with an intact membrane. Its frequency was significantly $(p<0.05)$ augmented in phorate exposed erythrocytes of fish of treated groups, in contrast, to control in a dose-dependent manner. Evidently, the brighter fluorescence was observed due to nuclear condensation in phorate exposed erythrocytes of $C$. punctatus of treated groups (T1 and T2) with respect to the unexposed group (Fig. 7). Similarly, Mai et al. (2010) have also reported the induction of apoptosis in terms of condensed or fragmented nuclei in tilapia blood cells. Markedly, the representative photographic images exemplify phorate-induced condensed/rounded nuclei (CRN) in erythrocytes of test fish of T1 (Fig. 7C) and T2 (Fig. 7D) in comparison with the control (Fig. 7B). Subsequently, the genetic material becomes more susceptible for damage. Further, enhanced membrane permeability also facilitates the transport of caspase-independent factors, particularly apoptosis inducing factor (AIF) and mitochondrial endonuclease $G$ (endo $G$ ) to the nucleus via cytoplasm (Candé et al., 2002). In the nucleus, these factors become instrumental for condensation and fragmentation of chromatin or DNA strands which engenders various nuclear anomalies (Tebourbi et al., 2011). Eventually, the aforesaid data related to nuclear abnormalities were significantly $(p<0.05)$ increased in phorate exposed erythrocytes of fish in comparison with the control in a dose-dependent manner. Moreover, Walia et al. (2013) and Noor and Zutshi (2018) have also reported induction of NAs in blood cells of fish, Labio rohita.

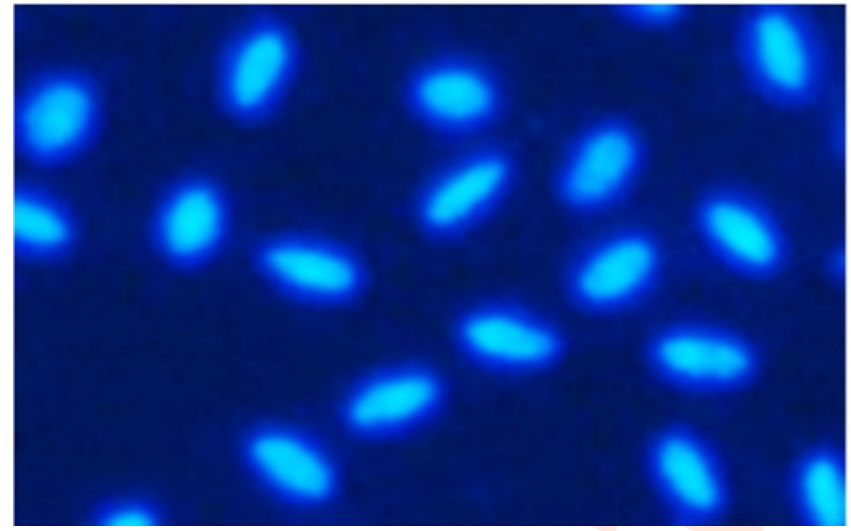

(A) Control (without NAs)

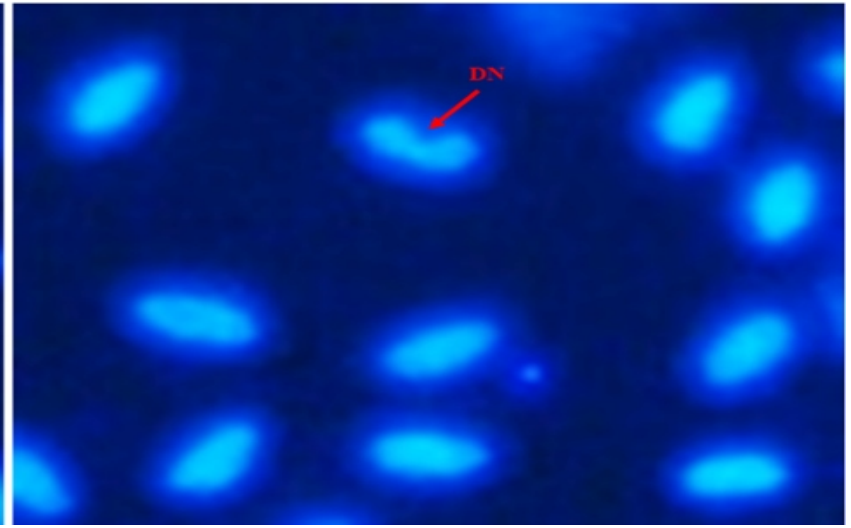

(B) Dumbbell Nucleus

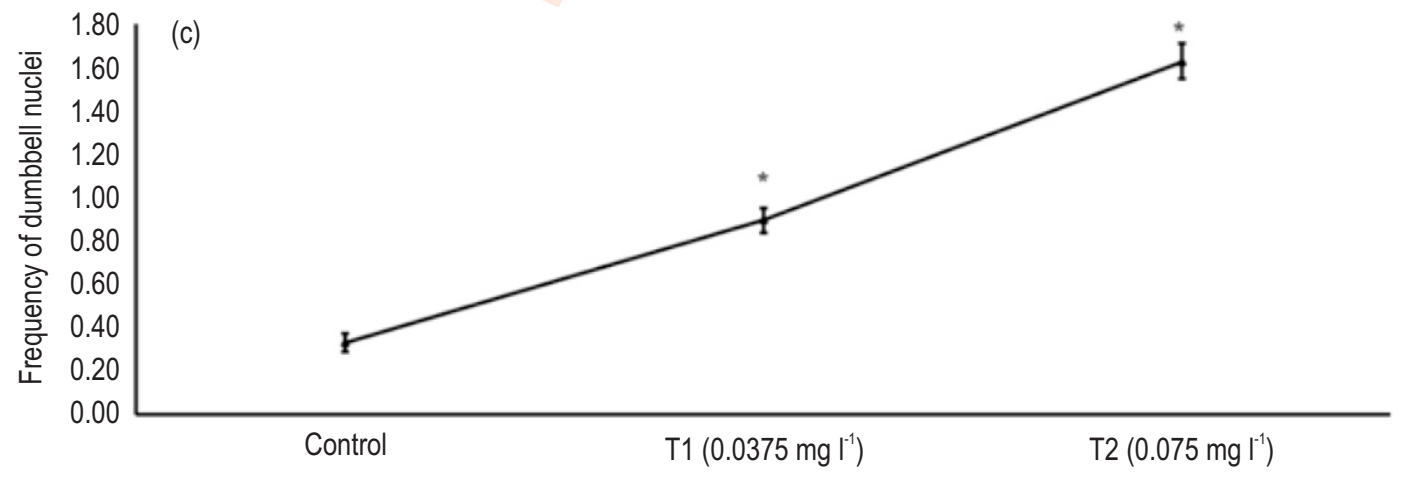

Fig. 6 : Photographic images showing the dumbbell nucleus $(D N)(B)$ in phorate exposed erythrocytes of fish in comparison to control (without DN) (A) by using Hoechst $33342\left(1.5 \mathrm{mg} \mathrm{m}^{-1}\right)$ fluorescent dye. (C) A graph showing a significant $(p<0.05)$ induction in frequencies of dumbbell nuclei (DN) in phorate induced erythrocytes of fish of T1 and T2 in comparison to control after $30 \mathrm{~d}$. Values are mean \pm SEM of 9 fish from each group. * indicated significance at $p<0.05$ of treated against control. 


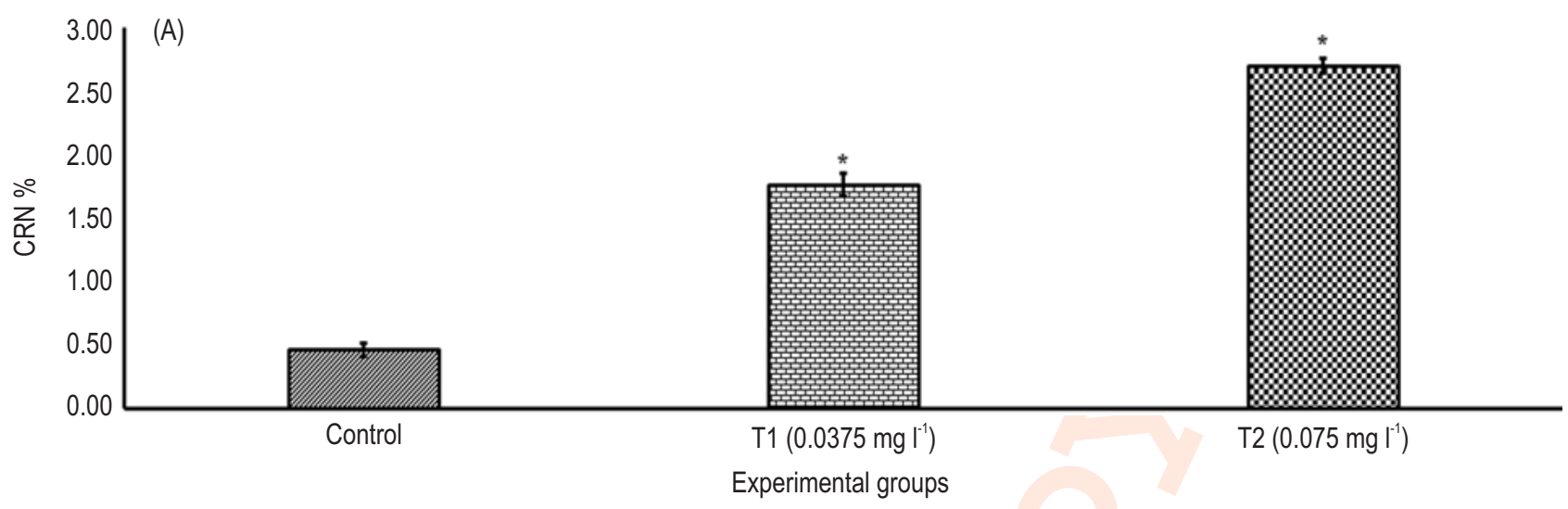

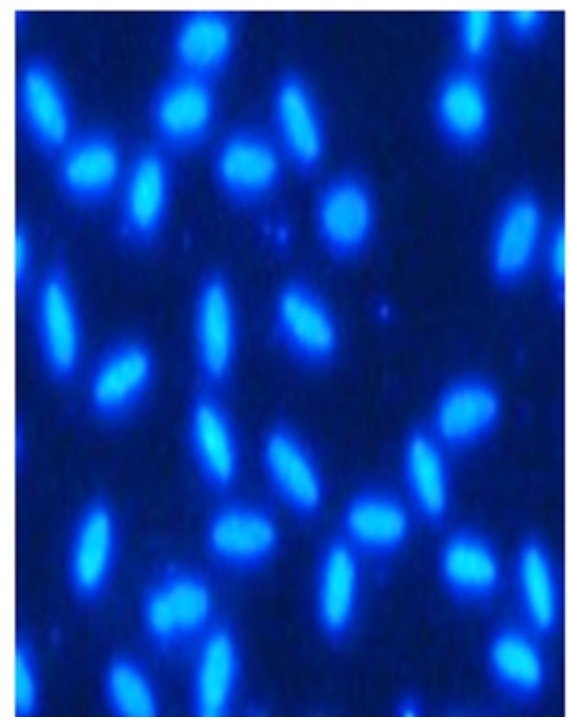

(B) Control

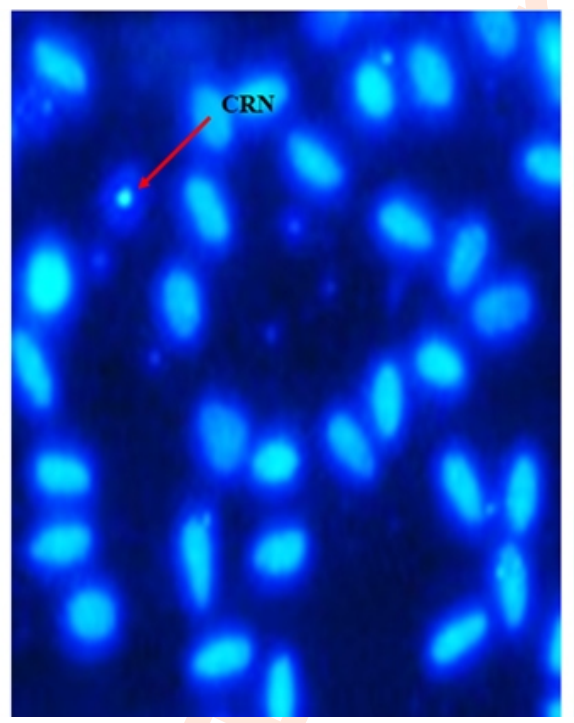

(C) $\mathrm{T} 1\left(0.0375 \mathrm{mg} \mathrm{l}^{-1}\right)$

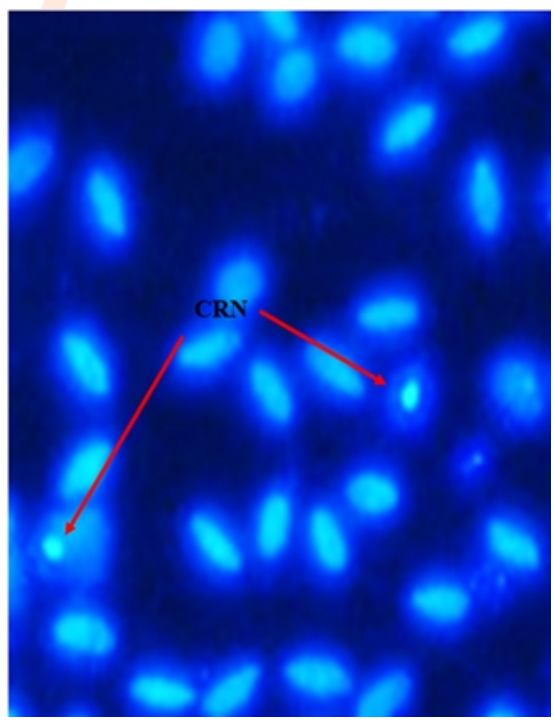

(D) T2 $\left(0.075 \mathrm{mg} \mathrm{l}^{-1}\right)$

Fig. 7 : (A) Graph showing a significant $(p<0.05)$ induction in frequencies of condensed/rounded nuclei $(C R N)$ in phorate exposed erythrocytes of fish of $\mathrm{T} 1$ and $\mathrm{T} 2$ in comparison to control after $30 \mathrm{~d}$. The photographic images of erythrocytes showing CRN (by arrows) in T1 (C) and T2 (D) in comparison to control (B) by using Hoechst 33342 fluorescent dye $\left(1.5 \mathrm{mg} \mathrm{ml}^{-1}\right)$ in phorate exposed fish C. punctatus. Values are mean \pm SEM of 9 fish from each group. * indicated significance at $p<0.05$ of treated against control.

The correlation analysis illustrates a prominent correlation between the phorate induced ROS and consequent nuclear abnormalities in erythrocytes of Channa punctatus after 30 days of treatment. Notably, the correlation analysis also displays the compact relationships among the phoarte induced ROS and various NAs with greater values of coefficient of correlation $(R)$ in erythrocytes of treated fish. Comparatively, the highest correlation coefficient was found for MN and the lowest for VN. Thus, the values of correlation coefficients clearly illustrate the sensitivity of nuclear anomalies as a predictor of phorate toxicity in the test fish. Accordingly, the pattern of their sensitivity was stipulated as follows; $\mathrm{MN}>\mathrm{NN}>\mathrm{CN}>\mathrm{CRN}>\mathrm{NBUD}>\mathrm{NPB}>$ $\mathrm{BN}>\mathrm{DN}>\mathrm{KN}>\mathrm{VN}$.

The chronic exposure of phorate generates cellular stress in fish. This culminates into genotoxicological impairments like MN and other NAs. Thus, the extent of expression of nuclear abnormalities can be amply employed in molecular biomonitoring of stressed aquatic regimes. Further, their estimation is cost effective, viable, precise and with lesser involvement of high-throughput technologies. Present findings, too, successfully establish their role as sensitive biomarkers in monitoring the health status of fishes inhabiting aquatic regimes contaminated with phorate.

\section{Acknowledgments}

Authors are thankful to the Head, Department of Zoology, University of Lucknow- 226007 for providing research facilities. Financial support rendered by Council of Scientific and Industrial Research (CSIR) and the University Grants Commission (UGC), New Delhi, as CSIR-SRF (Vide No. 09/107(366)/2012-EMR-I) to 
Arun Ratn and BSR-fellowship (File No. 25-1/2014-2015 (BSR)/7-109/2007/BSR) to Yashika Awasthi, respectively, is gratefully acknowledged. We are also thankful to FIST and PURSE facilities of Department of Science and Technology, Government of India and the Special Assistance Programme (SAP) of the UGC.

\section{Add-on Information}

Author's contribution : S. P. Trivedi: Conceptualization, Experimental designing, final editing of the MS \& proof correction; A. Ratn : Execution of the Experiment and analysis of nuclear abnormalities; Y. Awasthi : Photography and estimation of ROS and nuclear abnormalities; N. Gupta: Statistical analysis of the data and critical evaluation of the MS; M. Kumar: Supervision of the experiment \& preparation of the preliminary manuscript; A.Trivedi: Plotting of Graphs, tabulation and overall analysis of the data.

Research content: The research content of manuscript is original and has not been published elsewhere.

Ethical approval : For entire experimentation and euthanization of fish, necessary guidelines issued by the Institutional Animal Ethics Committee (IAEC, Registration No. 1861/GO/Re/S/16/ CPCSEA) were followed.

Conflict of interest : The authors declare that there is no conflict of interest.

\section{Data from other sources : Not applicable}

Consent to publish : All authors agree to publish the paper in Journal of Environmental Biology.

\section{References}

Abhilash P.C. and N. Singh: Pesticide use and application: An Indian scenario. J. Hazard Mater., 165, 1-12 (2009).

Ahmad, I. and M. Ahmad: Freshwater fish, Channa punctatus, as a model for pendimethalin genotoxicity testing: A new approach toward aquatic environmental contaminants. Environ. Toxicol., 31, 15201529 (2016).

Aktar M.W., D. Sengupta and A. Chowdhury: Impact of pesticides use in agriculture: their benefits and hazards. Interdiscip. Toxicol., 2, 1-12 (2009).

Alavanja, M.C.R.: Pesticides use and exposure extensive worldwide. Rev. Environ. Hlth., 24, 303-309 (2009).

Ateeq, B., M. Abul farah, M. Niamat Ali and W. Ahmad: Induction of micronuclei and erythrocyte alterations in the catfish Clarias batrachus by 2, 4-dichlorophenoxyacetic acid and butachlor. Mutat. Res., 518, 135-144 (2002).

Awasthi, Y., A. Ratn, R. Prasad, M. Kumar and S.P. Trivedi: An in-vivo analysis of $\mathrm{Cr}^{6+}$ induced biochemical, genotoxicological and transcriptional profiling of genes related to oxidative stress, DNA damage and apoptosis in liver of fish, Channa punctatus (Bloch, 1793). Aquat. Toxicol., 200, 158-167 (2018).
Bhardwaj T. and J.P. Sharma: Impact of pesticides application in agricultural industry: An Indian Scenario. Int. J. Agric. Food Sci. Technol., 4, 817-822 (2013).

Candé, C., I. Cohen and E. Daugas: Apoptosis-inducing factor (AIF): A novel caspase-independent death effector released from mitochondria. Biochimie., 84, 215-222 (2002).

Chaudhari, R. and K.K. Saxena: Genotoxic evaluation of fenvalerate in Channa punctatus by micronucleus test. J. Sci. Res. Tech., 3, 30-33 (2015).

Chondrou, V., K. Trochoutsou, A. Panayides, M. Efthimiou, G. Stephanou and N.A. Demopoulos: Combined study on clastogenic, aneugenic and apoptotic properties of doxorubicin in human cells in vitro. J. Biol. Res. (Thessalonike, Greece), 25, 17 (2018).

Coskun, M., M. Coskun, A. Cayir and O. Ozdemir: Frequencies of micronuclei (MNi), nucleoplasmic bridges (NPBs), and nuclear buds (NBUDs) in farmers exposed to pesticides in Çanakkale, Turkey. Environ. Int., 37, 93-96 (2011).

Crupkin, A.C., P. Carriquiriborde, J. Mendieta, A.M. Panzeri, M.L. Ballesteros, K.S.B. Miglioranza and M.L. Menone: Oxidative stress and genotoxicity in the South American cichlid, Australoheros facetus, after short-term sublethal exposure to endosulfan. Pestic. Biochem. Physiol., 105, 102-110 (2013).

da Rocha, C.A.M., G.C. da Fonseca, R.F.G. Ribeiro and R.H. da Silva Pinheiro: Detection of micronuclei and other nuclear abnormalities in Oreochromis niloticus exposed to potassium dichromate. Glob. Vet., 7, 301-304 (2011).

da Silva Souza, T. and C.S. Fontanetti: Micronucleus test and observation of nuclear alterations in erythrocytes of Nile tilapia exposed to waters affected by refinery effluent. Mutat. Res. Toxicol. Environ. Mutagen., 605, 87-93 (2006).

Falfushynska, H.I., L.L. Gnatyshyna and O.B. Stoliar: Effect of in-situ exposure history on the molecular responses of freshwater bivalve Anodonta anatina (Unionidae) to trace metals. Ecotoxicol. Environ. Saf., 89, 73-83 (2013).

Fenech, M.: Cytokinesis-block micronucleus assay evolves into a "cytome" assay of chromosomal instability, mitotic dysfunction and cell death. Mutat. Res. Mol. Mech. Mutagen., 600, 58-66 (2006).

Fenech, M., M. Kirsch-Volders, A.T. Natarajan, J. Surralles, J.W. Crott, J. Parry, H. Norppa, D.A. Eastmond, J.D. Tucker and P. Thomas: Molecular mechanisms of micronucleus, nucleoplasmic bridge and nuclear bud formation in mammalian and human cells. Mutagenesis, 26, 125-132 (2011).

Garaj-Vrhovac, V., G. Gajski and S. Ravlic: Efficacy of HUMN criteria for scoring the micronucleus assay in human lymphocytes exposed to a low concentration of $p, p^{\prime}-$ DDT. Brazilian J. Med. Biol. Res., 41, 473-476 (2008).

Gill, H.K. and H. Garg: Pesticides: Environmental Impacts and Management Strategies. In: Pesticides-Toxic Aspects. INTECH, pp. 187-230 (2014).

Godek, K.M., L. Kabeche and D.A. Compton: Regulation of kinetochoremicrotubule attachments through homeostatic control during mitosis. Nat. Rev. Mol. Cell. Biol., 16, 57-64 (2015).

Hodgson, E.: Pesticide Biotransformation and Disposition. $1^{15}$ Edn., North Carolina State University, Raleigh, NC, USA(2012).

Holland, N.T., P. Duramad, N. Rothman, L. W. Figgs, A. Blair, A. Hubbard and M.T. Smith: Micronucleus frequency and proliferation in human lymphocytes after exposure to herbicide 2,4dichlorophenoxyacetic acid in-vitro and in-vivo. Mutat. Res., 521, 
165-178 (2002).

larmarcovai, G., S. Bonassi and A. Botta: Genetic polymorphisms and micronucleus formation: A review of the literature. Mutat. Res. Mutat. Res., 658, 215-233 (2008).

Kirsch-Volders, M. and M. Fenech: Inclusion of micronuclei in nondivided mononuclear lymphocytes and necrosis/apoptosis may provide a more comprehensive cytokinesis block micronucleus assay for biomonitoring purposes. Mutagenesis, 16, 51-58 (2001).

Klobučar, G.I.V., A. Štambuk, M. Pavlica, P. Sertić, K. H. Mirela and K. H. Branimir: Genotoxicity monitoring of freshwater environments using caged carp (Cyprinus carpio). Ecotoxicology, 19, 77-84 (2010).

Lindberg, H.K., X. Wang, H. Järventaus, G.C.M. Falck, H. Norppa and M. Fenech: Origin of nuclear buds and micronuclei in normal and folate-deprived human lymphocytes. Mutat. Res. Mol. Mech. Mutagen., 617, 33-45 (2007).

Mai, W., J. Yan, L. Wang, Y. Zheng, Y. Xin and W. Wang: Acute acidic exposure induces p53-mediated oxidative stress and DNA damage in tilapia (Oreochromis niloticus) blood cells. Aquat. Toxicol., 100, 271-281 (2010).

Marques, A., M. Custódio, S. Guilherme, I. Gaivão, M.A. Santos and M. Pacheco: Assessment of chromosomal damage induced by a deltamethrin-based insecticide in fish (Anguilla anguilla L.)-A follow-up study upon exposure and post-exposure periods. Pestic. Biochem. Physiol., 113, 40-46 (2014).

Mostafalou, S. and M. Abdollahi: Pesticides and human chronic diseases: Evidences, mechanisms, and perspectives. Toxicol. Appl. Pharmacol., 268, 157-177 (2013).

Murphy, M.P.: How mitochondria produce reactive oxygen species. Biochem. J., 417, 1-13(2009).

Myers, J.P., M.N. Antoniou and B. Blumberg: Concerns over use of glyphosate-based herbicides and risks associated with exposures: a consensus statement. Environ. Hlth., 15, 1-13 (2016)

Noor, N. and B. Zutshi: Monitoring of nuclear abnormality frequencies as indicators of environmental pollution in peripheral erythrocytes of Labeo rohita Reared in Lakes of Bangalore. J. Ecophysiol. Occup. Hlth., 18, 86-102 (2018).

Pandey, A.K., N.S. Nagpure and S.P. Trivedi: Evaluation of genotoxicity of profenofos to freshwater fish Channa punctatus (Bloch) using the micronucleus assay. African J. Biotechnol., 13, 3985-3988 (2014).

Podrimaj-Bytyqi, A., A. Borovečki, Q. Selimi, S. Manxhuka-Kerliu, G. Gashi and I.R. Elezaj: The frequencies of micronuclei, nucleoplasmic bridges and nuclear buds as biomarkers of genomic instability in patients with urothelial cell carcinoma. Sci. Rep., 8, 1-9 (2018)

Ratn, A., Y. Awasthi, M. Kumar, S.K. Singh, R. Tripathi and S.P. Trivedi: Phorate induced oxidative stress, DNA damage and differential expression of $\mathrm{p} 53$, apaf- 1 and cat genes in fish, Channa punctatus (Bloch, 1793). Chemosphere, 182, 382-391 (2017).

Ratn, A., R. Prasad, Y. Awasthi, M. Kumar, A. Misra and S.P. Trivedi: $\mathrm{Zn}^{2+}$ induced molecular responses associated with oxidative stress, DNA damage and histopathological lesions in liver and kidney of the fish, Channa punctatus (Bloch, 1793). Ecotoxicol. Environ. Saf., 151, 10-20 (2018).

Saquib, Q., S.M. Attia and M.A. Siddiqui: Phorate-induced oxidative stress, DNA damage and transcriptional activation of p53 and caspase genes in male Wistar rats. Toxicol. Appl. Pharmacol., 259, 54-65 (2012).

Serrano-García, L. and R. Montero-Montoya: Micronuclei and chromatid buds are the result of related genotoxic events. Environ. Mol. Mutagen., 38, 38-45 (2001).

Slaninova, A., M. Smutna, H. Modra and Z. Svobodova: A review: Oxidative stress in fish induced by pesticides. Neuroendocrinol. Lett., 30, 2-12 (2009).

Tebourbi, O., M. Sakly and K. Ben Rhouma: Molecular mechanisms of pesticide toxicity. In: Pesticides in the Modern World- Pests Control and Pesticides Exposure and Toxicity Assessment (Ed.: M. Stoytecheva), Intech Open Limited, 5, Princes Gate Court, London-SW72QJ, 297-332 (2011). (http://www. intechopen.com/books/pesticides-in-the-modern-world-pestscontrol-and-pesticides-exposure-andtoxicity-assessment/ molecular-mechanisms-of-pesticide-toxicity).

Thomas, P., K. Umegaki and M. Fenech: Nucleoplasmic bridges are a sensitive measure of chromosome rearrangement in the cytokinesis-block micronucleus assay. Mutagenesis, 18, 187-194 (2003).

Tiwari, V. and S.P. Trivedi: Investigations on remedial role of Rauwolfia serpentina root extract against carbofuran formulation induced genotoxicity in Channa punctatus. J. Environ. Biol., 40, 1023-1028 (2019).

Trivedi, S.P., R. Prasad and A.A. Khan: Amelioration potential of Withania sonmifera root extract on hexavalent chromium induced micronucleus in Channa punctatus (Bloch, 1793). J. Environ. Biol., 41,672-679 (2020).

Trivedi, S.P., A. Ratn, Y. Awasthi, M. Kumar and A. Trivedi: In vivo assessment of dichlorovos induced histological and biochemical impiarements coupled with expression of p53 responsive apoptotic genes in the liver and kidney of fish, Channa punctatus (Bloch, 1793). Comp. Biochem. Physiol. Part C, 245, 109032 (2021).

Velisek, J., A. Stara, J. Kolarova and Z. Svobodova: Biochemical, physiological and morfological responses in common carp (Cyprinus carpio L.) after long-term exposure to terbutryn in real environmental concentration. Pestic. Biochem. Physiol., 100, 305-313 (2011).

Walia, G.K., D. Handa, H. Kaur and R. Kalotra: Erythrocyte abnormalities in a freshwater fish, Labeo rohita exposed to tannery industry effluent. Int. J. Pharm. Biol. Sci., 3, 287-295 (2013).

Weldetinsae, A., M. Dawit, A. Getahun, H.S. Patil, E. Alemayehu, M. Gizaw, M. Abate and D. Abera: Aneugenicity and clastogenicity in freshwater fish Oreochromis niloticus exposed to incipient safe concentration of tannery effluent. Ecotoxicol. Environ. Saf., 138, 98-104 (2017).

Yadav, K.K. and S.P. Trivedi: Sublethal exposure of heavy metals induces micronuclei in fish, Channa punctata. Chemosphere, 77 , 1495-1500 (2009). 